\title{
STUDY OF FIELD EFFECT TRANSISTORS FOR THE SODIUM ION DETECTION USING FLUOROPOLYSILOXANE-BASED SENSITIVE LAYERS
}

\author{
A. Cazalé ${ }^{1,2,3}$, W. Sant ${ }^{1}$, J. Launay ${ }^{2,3}$, F. Ginot ${ }^{1}$, P. Temple-Boyer ${ }^{2,3}$
}

1) HEMODIA SA, Rue du chêne vert, BP88205, F-31682 Labège, France

2) CNRS, LAAS, 7 avenue du colonel Roche, F-31400 Toulouse, France

3) University of Toulouse; UPS; LAAS; F-31400 Toulouse, France

\begin{abstract}
A membrane for the development of $\mathrm{Na}^{+}$sodium ion sensitive field effect transistor ( $\mathrm{pNa}-$ ISFET) is described in this work. This membrane is based on a fluoropolysiloxane (FPSX) polymer modified by sodium ionophore. The advantages of using such polymer are several: it permits good adhesion properties on silicon-based layers, it is characterized by a lower resistivity and it is fully compatible with ink jet printing technique. Thus, FPSX membranes were developed in the frame of a $\mathrm{pH}-\mathrm{ChemFET} / \mathrm{Ag} / \mathrm{AgCl}$ reference electrode industrial fabrication process. Studies involve the deposition of FPSX-based, sodium ion sensitive layers by ink jet printing, the integration and characterization of $\mathrm{Ag} / \mathrm{AgCl}$ reference electrode, as well as the $\mathrm{pNa}$ measurement in solution. Thus, whatever the reference electrode used, FPSX-based pNa-ISFET microsensors show good detection properties with sensitivity around $57 \mathrm{mV} / \mathrm{pNa}$, detection limit around $10^{-4} \mathrm{M}$, low $\mathrm{pH}$ interferences $\left(7 \mathrm{mV} / \mathrm{pH}\right.$ in the [9-12] basic range) and selectivity coefficient versus potassium $\mathrm{K}^{+}$ion -3 . Final application is done through analysis of real sweat samples.
\end{abstract}

Keywords: ISFET sensor, inkjet printing, ion-sensitive layers, sodium ion detection 


\section{Introduction}

With a concentration value around $140 \mathrm{mmol} / \mathrm{L}$, the sodium ion $\mathrm{Na}^{+}$plays a main role in the blood ionic equilibrium: any concentration variation leads to hyponatraemia or to hypernatraemia, both known to be responsible for numerous health disorders (dizziness, numbness, headaches,...). Thus, the sodium ion detection was investigated for point of care applications. In order to do so, electrochemical detection/transduction principles seem to have the best potentialities. However, since the sodium ion is not electrochemically active, amperometry cannot be used and efforts were focused on potentiometry. As a result, potentiometric sensors such as ion-sensitive electrodes (ISE) or ion-sensitive field effect transistors (ISFET) were adapted to the sodium ion detection using varied ion-sensitive layers and associated integration processes.

These ion-sensitive layers, also called ISM (Ion-Sensitive Membranes), play a crucial role in an industrial mass fabrication process, whose aim is of course commercial. The choice of the integration method will depend about the ISM nature that can be organic (polymers) or inorganic (mainly silicon-based). For example, silicon nitride $\left(\mathrm{Si}_{3} \mathrm{~N}_{4}\right)$ was characterized by low detection sensitivity and selectivity [1]. Sodium aluminosilicate $\mathrm{Na}-\mathrm{AlSi}_{3} \mathrm{O}_{8}$ or NAS glass were also studied, evidencing better sensitivity and selectivity according to the ion implantation process [2-3]. Unfortunately, if such process is compatible with mass fabrication at low cost, it was finally not convenient for silicon foundries since it requires implantation of sodium ions $\mathrm{Na}^{+}$at low energy. Furthermore, the so-obtained inorganic materials did not show a sufficient selectivity toward potassium and hydronium/hydroxyde ions.

In order to develop specific ion-sensitive organic membranes, the use of $\mathrm{Na}^{+}$ion ionophores and associated polymers offers also great performances, improved flexibility, and multiples integration ways. As the most used polymer matrix for microelectrodes [4], poly vinyl chloride (PVC) was adapted to ChemFET devices [5-8]. One of the simplest methods for deposit this kind of 
polymer based, ion-sensitive membranes consists in drop coating. Using simple tools, this technique allows the quick deposition of ion-sensitive layers in order to study their detection properties (sensitivity, selectivity...). Nevertheless, since such process is not automated, it results in a weak reproducibility that prevent from any industrial functionalization process.

Anyway, integration at wafer level can be achieved by coupling photolithography methods with spin-coating deposition techniques, using photosensitive polymers such as polyurethane (PU) [9-10] or polysiloxane (PSX) [11]. Nevertheless, such process implies to waste the major part of the polymer with the specific and expensive ionophores. As a result, such integration process does not fit with a low cost fabrication strategy. In addition, this integration method prevents from realising ion-sensitive multi-layers and multi-ions analysis devices. To deal with these requirements, ChemFET devices have been developed while integrating biochemical-sensitive membranes by inkjet printing [12]. In the frame of chemical-sensitive membranes, two serious candidates are available. The first one is still polyvinyl chloride (PVC). However, this polymer suffers of adhesion problems on the ISFET dielectric gate, leading to low lifetimes and excessive drifts [13]. Moreover, because its use requires addition of plasticizers and because evaporation phenomena of its organic solvent (tetrahydrofuran THF) are quite important, the PVC matrix becomes rapidly too viscous to be deposited by ink jet printing techniques, preventing from developing a fully reproducible integration process. The other promising polymer is polysiloxane (PSX). In this case, since no plasticizer is required and even if tetrahydrofuran (THF) is used as solvent, evaporation phenomena are lowered, adhesion properties on silicon-based dielectrics are improved, and ink-jet deposition is conceivable $[14,15]$. As a result, ion-sensitive, polysiloxane-based layers have shown good performances in terms of integration process and detection properties (sensibility, selectivity, response time, drift and lifetime) [16-19]. Nevertheless, the PSX polymer is still characterized by too high electrical resistivity to optimize fully detection properties. To tackle off this last bottleneck, the use of the fluoropolysiloxane (FPSX) polymers was finally proposed [20, 21]. 
This paper presents the industrial development of pNa-ISFET microsensors for the sodium ion concentration measurement in liquid phase. It focuses on the adaptation of $\mathrm{pH}-\mathrm{ChemFET}(\mathrm{pH}-$ sensitive chemical field effect transistors) microsensors to the $\mathrm{Na}^{+}$ion detection using fluoropolysiloxane (FPSX) polymer. Therefore, starting from a pH-ChemFET technology based on silicon-based microtechnologies and "Smart cards" techniques, it deals with the integration of $\mathrm{Ag} / \mathrm{AgCl}$ reference electrodes for the liquid phase analysis, with the ink jet printing of FPSX-based ion-sensitive layers and with the study of the pNa-ISFET microsensors detection performances.

\section{Experimental}

\subsection{Microsensors fabrication}

P-well, N-channel, $\mathrm{SiO}_{2} / \mathrm{Si}_{3} \mathrm{~N}_{4}$-gate, $\mathrm{pH}$-sensitive chemical field effect transistors $(\mathrm{pH}$ ChemFET) were fabricated on 6-inch, (100)-oriented, N-type (500 $\Omega . \mathrm{cm})$ silicon wafers in a silicon foundry in order to reach fully mass fabrication at low cost, reproducibility, and high fabrication yield (figure 1). This $\mathrm{SiO}_{2} / \mathrm{Si}_{3} \mathrm{~N}_{4}-\mathrm{pH}-\mathrm{ChemFET}$ technology was already studied in previous works evidencing quasi-Nernstian $\mathrm{pH}$ responses (sensitivity around $53 \mathrm{mV} / \mathrm{pH}$ ), detection accuracy around $1 \mathrm{mV}$ or $0.02 \mathrm{pH}$, maximal drift lower than $5 \mathrm{mV} /$ day and lifetime higher than four months $[12,22]$. Then, "Smart cards" techniques were used in order to reach automated, mass fabrication/packaging processes [12]. Two pH-ChemFET chips (size: 2.1 x $1.6 \mathrm{~mm}^{2}$ ) were packaged and connected on a specific printed circuit board (called "module" hereafter).

The sodium ion detection was investigated using a specific ion-sensitive layer based on fluoropolysiloxane (FPSX) polymer purchased from Dow Corning (730 RTV). The ion-sensitive mixture was made of $300 \mathrm{mg}$ of FPSX centrifuged in $1.5 \mathrm{ml}$ of tetrahydrofuran (to eliminate the binder that causes non-optimal functioning), $10 \mathrm{mg}$ of sodium ionophores (4-tertbutylcalix[4]arene-tetra-acetic acid tetraethyl ester), purchased from Sigma-Aldrich under the name 
of sodium ionophore $\mathrm{X}$ ), $5 \mathrm{mg}$ of ionic additives (sodium tetrakis [3,5-bis(1,1,1,3,3,3-hexafluoro-2methoxy-2-propyl)phenyl]borate trihydrate, purchased from Sigma-Aldrich). This membrane solution was mixed in an ultrasonic bath (duration: 30 minutes) to insure homogeneity, and was deposited by means of a custom "drop on demand" ink jet prototype. Finally, the reticulation reaction was performed at ambient temperature thanks to atmospheric moisture (figure 2) [23].

At first, deposition parameters (ejection pressure and duration) influences were studied by characterizing the topology of FPSX membranes deposited on borosilicate substrates. Then, optimized sodium-sensitive membranes were deposited on the $\mathrm{pH}$-ChemFET sensitive area according to industrial specifications, keeping in mind process reproducibility.

So, the first $\mathrm{SiO}_{2} / \mathrm{Si}_{3} \mathrm{~N}_{4}$ ChemFET chip was adapted to the sodium ion detection, leading to the realisation of the $\mathrm{SiO}_{2} / \mathrm{Si}_{3} \mathrm{~N}_{4} / \mathrm{FPSX} \mathrm{Na}{ }^{+}$ion-sensitive field effect transistor (pNa-ISFET) while the second chip was used as a $\mathrm{pH}$-sensitive field effect transistor (pH-ChemFET). Finally, an $\mathrm{Ag} / \mathrm{AgCl}$ gate reference electrode was integrated on the $\mathrm{pNa}-\mathrm{ISFET} / \mathrm{pH}-\mathrm{ChemFET}$ detection module (figure 3). In order to do so, $5 \mathrm{mg}$ of $\mathrm{Ag} / \mathrm{AgCl}$ ink (90/10 $\mathrm{Ag} / \mathrm{AgCl}$ ratio purchased from Gwent group) was dip coated on a specific contact located on the detection module, at equivalent distance from the two chips. This ink was finally stabilized by thermal annealing at $60^{\circ} \mathrm{C}$ for 30 minutes.

\subsection{Electrochemical measurements}

The electrochemical properties of the integrated " $\mathrm{Ag} / \mathrm{AgCl}$ ink" gate reference electrode were first studied by potentiometry. Using a Metrohm Autolab PGSTAT 30 potentiometer and a commercial reference electrode (Metrohm $\mathrm{Ag} / \mathrm{AgCl}$ glass double junction, with inner and outer compartment filled with $\mathrm{KCl} 3.5 \mathrm{M}$ ), Nernst potential at equilibrium were recorded in solutions consisting of a background electrolyte $\left(\mathrm{CH}_{3} \mathrm{COOLi} \quad 0.1 \mathrm{M}\right)$ with sodium chloride $\mathrm{NaCl}$ 
concentrations ranging from $10^{-2}$ to $10^{-1} \mathrm{M}$. Thus, the chloride ion $\mathrm{Cl}^{-}$detection properties as well as the temporal stability were effectively studied.

Electrical measurements were performed while biasing the $\mathrm{Ag} / \mathrm{AgCl}$ gate reference electrode and therefore the studied solution to the mass $\left(\mathrm{V}_{\mathrm{G}}=0\right)$ and working with constant drain-source voltage $V_{D S}$ and drain-source current IDS (typically $V_{D S}=2 \mathrm{~V}$ and IDS $=0.1 \mathrm{~mA}$ ) in order to work in saturation mode. A specific potentiometric ChemFET-meter electronic interface was used to monitor continuously the gate-source voltage $\mathrm{V}_{\mathrm{GS}}$ of both pNa-ISFET and $\mathrm{pH}-\mathrm{ChemFET}$ microsensors. A specific data treatment were developed: an analog-to-digital convector sampled the output voltage useful signal at $1 \mathrm{~Hz}$ and a microprocessor was finally responsible for an average procedure every 5 seconds. This was introduced to improve the signal to noise ratio, leading finally to a measurement display with a $0.2 \mathrm{~Hz}$ sampling frequency.

First, standard $\mathrm{pH}$ titration curve using hydrochloric acid $\left(\mathrm{HCl}: 10^{-2} \mathrm{M}\right)$ and tetra-methylammonium hydroxide (TMAH: $10^{-1} \mathrm{M}$ ) was performed to study the pNa-ISFET dependence to $\mathrm{pH}$. Then, $\mathrm{pNa}$ measurements were performed in lithium acetate solutions $\left(\mathrm{CH}_{3} \mathrm{COOLi} 0.1 \mathrm{M}\right)$ with various concentrations of sodium chloride $\mathrm{NaCl}$ (ranging from $10^{-5}$ to $10^{0} \mathrm{M}$ ) and potassium chloride $\mathrm{KCl}$ (ranging from $5 \times 10^{-3}$ to $10^{0} \mathrm{M}$ ). Thus, pNa-ISFET analytical responses were analyzed and the potentiometric selectivity coefficient $\left(\log \mathrm{K}_{\mathrm{Na}+/ \mathrm{K}+}\right)$ was found out according to the fixed interference (FIM) [24].

\section{Results and discussion}

\subsection{Integration of fluoropolysiloxane-based layers by ink jet printing}

Ink jet printing techniques were studied for the deposition of fluoropolysiloxane/tetrahydrofuran (FPSX/THF) solutions. Whatever the ejection parameters, i.e. pressure $\Delta \mathrm{P}$ and time tejection, and after FPSX reticulation at ambient temperature and THF 
evaporation, FPSX membranes were comparable to spherical segments (figure 4). Their main geometrical parameters, i.e. the upper and lower radii a and $\mathrm{b}$ as well as the height $\mathrm{h}$, were determined as a function of injection time for an injection pressure $\Delta \mathrm{P}$ around $48.3 \mathrm{~Pa}$, showing logically increasing values (table 1). Nevertheless and taking into account to measurement errors, it appeared that all the FPSX patterns are homothetic whatever the ejection time, i.e. that their $\mathrm{a} / \mathrm{b}$ and $\mathrm{h} / \mathrm{b}$ ratios are constant, estimated roughly around 0.4 and 0.015 respectively $(\Delta \mathrm{P} \approx 48.3 \mathrm{~Pa})$. Considering a spherical segment, the FPSX patterns volume is finally given by:

$\mathrm{x}$

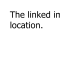

Thus according to experimental values and calculations, ink jet printing technique allowed the controlled deposition of FPSX patterns with a wide range of thickness (from 7.5 to $17.5 \mu \mathrm{m}$ ), deposition area (from 0.25 to $1 \mathrm{~mm}^{2} \mu \mathrm{m}$ ) and volume (from 5 to $40 \mathrm{~nL}$ ).

Since the addition of chemical species in small quantities (such as ionophores) into the FPSX/THF solution did not have any influence on the deposition properties, this technique was used for the integration of ion-sensitive layers for ISFET applications. However, according to technological specifications, the lower radius had to be lower than 500 micrometres. In order to further decrease this value, it was necessary to decrease the ejection pressure. Thus, ejection pressure and time were respectively fixed at $34.5 \mathrm{~Pa}$ and $1 \mathrm{~ms}$, leading to the deposition of optimized FPSX-based $\mathrm{Na}^{+}$-sensitive membranes with the following characteristics: form: spherical segment, lower radius: $460 \mu \mathrm{m}$, upper radius: $185 \mu \mathrm{m}$, thickness: $6 \mu \mathrm{m}$, deposition area: $0.66 \mathrm{~mm}^{2}$ and volume: $2.7 \mathrm{~nL}$ (figure 5).

\subsection{Characterization of the integrated " $\mathrm{Ag} / \mathrm{AgCl}$ ink" reference electrode}


In order to validate the integrated "Ag/AgCl ink" reference electrode, the chloride ion $\mathrm{Cl}^{-}$ concentration measurement in liquid phase was studied by potentiometry while using a Methrohm $\mathrm{Ag} / \mathrm{AgCl}$ glass double junction reference electrode. Typical analytical responses were obtained evidencing sensitivity around $55 \pm 1 \mathrm{mV} / \mathrm{pCl}$ on the $[0.01 \mathrm{M}-0.1 \mathrm{M}]$ concentration range (figures 6 and 7) $[25,26]$. Then, its stability was studied in a $0.1 \mathrm{M} \mathrm{NaCl}$ solution (figure 8). After an initial increase around $2 \mathrm{mV}$ during half an hour, the $\mathrm{Ag} / \mathrm{AgCl}$ microelectrode potential at equilibrium was found to be quite stable around $0.100 \mathrm{~V}$, evidencing a very low drift (around $1 \mu \mathrm{V} . \mathrm{s}^{-1}$ ) during the following hours in agreement with literature [27].

\subsection{Sodium ion $\mathrm{Na}^{+}$detection}

Before studying the $\mathrm{Na}^{+}$ion detection and since the FPSX-based ion-sensitive layers was deposited on a $\mathrm{pH}$-sensitive silicon nitride $\mathrm{Si}_{3} \mathrm{~N}_{4}$ film, the $\mathrm{pH}$ influence on the pNa-ISFET detection properties was checked experimentally. This was realized thanks to a standard HCl/TMAH titration experiment using the pNa-ISFET/pH-ChemFET module (figure 9). As expected, the $\mathrm{pH}-\mathrm{ChemFET}$ was able to monitor $\mathrm{pH}$ variations from 2 to 12 , evidencing sensitivity around $52 \mathrm{mV} / \mathrm{pH}$ [12]. In parallel, the pNa-ISFET was characterized by a constant response in the [2-9] pH range (sensitivity: $\sim 0 \mathrm{mV} / \mathrm{pH}$ ) and by a variation of $20 \mathrm{mV}$ in the [9-12] $\mathrm{pH}$ range (sensitivity: $7 \mathrm{mV} / \mathrm{pH}$ ). This $\mathrm{pH}$ sensitivity for basic solutions $(\mathrm{pH} \geq 9)$ was attributed to the presence of silanol groups in the fluoropolysiloxane matrix [28]. Such $\mathrm{pH}$ interference is relatively low compared to the sodium sensitivity (see hereafter) and can be neglected according to analysed solutions and applications.

Then, characterization studies were performed in solution of $\mathrm{CH}_{3} \mathrm{COOLi}\left(10^{-1} \mathrm{M}\right)$ chosen as carrier with various concentrations of sodium chloride (from $10^{-5}$ to $10^{-1} \mathrm{M}$ ) and/or potassium chloride $\mathrm{KCl}$ (from $5 \times 10^{-3}$ to $10^{0} \mathrm{M}$ ) in order to determine respectively the pNa-ISFET sensitivity to the sodium ion $\mathrm{Na}^{+}$as well as its selectivity to the potassium ion $\mathrm{K}^{+}$. Obtained analytical responses and calibration curves are shown in figures 10 and 11. It appears that the FPSX-based 
pNa-ISFET is characterized by a linear response in the $\left[10^{-4}-10^{0} \mathrm{M}\right]$ concentration range (sensitivity estimated for eight different sensors: $57 \pm 1 \mathrm{mV} / \mathrm{pNa}$ ). According to the fixed interference method (FIM), the potentiometric selectivity coefficient $\log \mathrm{K}_{\mathrm{Na}+/ \mathrm{K}+}$ was estimated to 3. Finally, response time, temporal drift and reproducibility of the FPSX-based pNa-ISFET were respectively estimated to 50 seconds and $0.3 \mathrm{mV} / \mathrm{h}$. Such results are similar to (or even better than) others described in the literature (table 2) $[5-8,10,16,21$,$] and are fully compatible with the$ natraemia analysis in biological fluids [4].

Then, in order to fully characterize the sodium microsensors, pNa-ISFET microdevices were studied while using the integrated $\mathrm{Ag} / \mathrm{AgCl}$ electrode on the detection module (rather than a commercial reference electrode as done previously). So, analytical responses and calibration curves still evidence typical linear variations with a sensitivity around $110 \mathrm{mV} /$ decade (figure 12 ). Such high sensitivity is related to the use of sodium chloride $(\mathrm{NaCl})$ based solution. It is roughly the sum between the pNa-ISFET sensitivity ( $55 \mathrm{mV} / \mathrm{pNa}$, see below) and the $\mathrm{Ag} / \mathrm{AgCl}$ microelectrode sensitivity to the chloride ion concentration $\left[\mathrm{Cl}^{-}\right](55 \mathrm{mV} / \mathrm{pCl}$, see section 3.2$)$. This shows that chloride ion $\mathrm{Cl}^{-}$has no effect on the pNa-ISFET detection properties but that measurement interferences will occur when using the pNa-ISFET - $\mathrm{Ag} / \mathrm{AgCl}$ electrode detection module. Such interferences will have to be taken into account by considering that the chloride ion concentration $\left[\mathrm{Cl}^{-}\right]$is constant or linearly related to the sodium ion concentration $\left[\mathrm{Na}^{+}\right]$according to the studied biological fluid (see hereafter).

Finally, since the sodium and chloride ions concentration ratio $\left[\mathrm{Na}^{+}\right] /\left[\mathrm{Cl}^{-}\right]$is known to be constant in biological fluids such as plasma or sweat (results not shown), the pNa-ISFET was suitable for the monitoring of sodium ion concentration in sweat. Since the collection of sweat samples requires specific protocol to prevent any dilution or fouling phenomena, a "non-classical" analytical method was used. After a pre-calibration made with five different sodium chloride $\mathrm{NaCl}$ solutions with various $(10,25,50,75$ and $100 \mathrm{mM})$, analysis was done thanks to the complete system by dropping off a small volume of real sweat on the pNa-ISFET sensitive surface. 
According to the calibration curve (figure 13), the sweat sample $\left[\mathrm{Na}^{+}\right]$concentration was estimated around $38.5 \pm 1 \mathrm{mM}$ whereas a $37 \pm 1 \mathrm{mM}$ value was obtained while using standard potentiometric analysis performed by an external laboratory. Such result demonstrates the pNa-ISFET microsensor use for real sweat samples analysis with a correct measurement accuracy according to the precalibration procedure.

\section{Conclusion}

PNa-ISFET microsensors were developed using silicon-based microtechnologies. The industrial process involved the mass fabrication of $\mathrm{pH}$-ChemFET transistors in silicon foundry, the deposition of fluoropolysiloxane-based, sodium ion $\mathrm{Na}^{+}$sensitive membranes by ink-jet printing and the final packaging process with an integrated " $\mathrm{Ag} / \mathrm{AgCl}$ ink" reference electrode. Thus, $\mathrm{pNa}$ ISFET microsensors were characterized by good detection properties (sensitivity: $57 \mathrm{mV} / \mathrm{pNa}$, detection limit: $10^{-4} \mathrm{M}$, low $\mathrm{pH}$ interferences: $7 \mathrm{mV} / \mathrm{pH}$ in the basic range, selectivity versus $\mathrm{K}^{+}$ion: $\left.10^{-3}\right)$. Finally, analysis of real sweat samples was successfully performed.

This FPSX-based ISFET / "Ag/AgCl ink" reference electrode technology is ready-to-use for the natraemia analysis in biological fluids such as plasmatic water, dialysate and/or sweat. Nevertheless, research works have still to be continued. First, $\mathrm{pCl}$ influences on the $\mathrm{pNa}$ measurement have to be studied according to analysed fluids. Second, $\mathrm{pH}$ interferences have to be controlled by differential measurement while using the pNa-ISFET/pH-ChemFET module. Third, specifications in terms of biocompatibility and lifetime have to be reached according to applications. Finally, this ion detection technology has to be developed for the on-line monitoring of the sodium ion $\mathrm{Na}^{+}$, and extended to other ions such as potassium $\mathrm{K}^{+}$and/or calcium $\mathrm{Ca}^{2+}$. Thus, it will be possible to analyse the physiological stress into sweat and/or the blood ionic equilibrium.

\section{References}


[1] B. Hajji, P. Temple-Boyer, J. Launay, T. Do Conto and A. Martinez: “pH, pK and pNa detection properties of $\mathrm{SiO}_{2} / \mathrm{Si}_{3} \mathrm{~N}_{4}$ ISFET chemical sensors", Microelectronics Reliability, 40 (2000) 783-786

[2] Z.M. Baccar, N. Jaffrezic-Renault, C. Martelet, H. Jaffrezic, G. Marest and A. Plantier: "Sodium microsensors based on ISFET/REFET prepared through an ion implantation process fully compatible with a standard silicon technology", Sensors and Actuators B, 32 (1996) 101105

[3] P-K. Shin and T. Mikolajick: " $\mathrm{H}^{+}, \mathrm{Na}^{+}$and $\mathrm{K}^{+}$ion sensing properties of sodium and aluminium co-implanted LPCVD silicon oxynitride thin films”, Applied Surface Science, 207 (2003) 351358

[4] U. Oesch, D. Amman and W. Simon: "Ion-selective membrane electrodes for clinical use", Clinical Chemistry, 32/8 (1986) 1448-1459

[5] U. Oesch, S. Caras and J. Janata: "Field effect transistors sensitive to sodium and ammonium ions", Analytical Chemistry, 53 (1981) 1983-1986

[6] M. Chudy, W. Wroblewski, A. Dybko and Z. Brzozka: "Multi-ion analysis based on versatile sensor head", Sensors and Actuators, B78 (2001) 320-325

[7] D.G. Pijanowska, E. Luboch, J.F. Biernat, M. Dawgul, W. Torbicz: "Na ${ }^{+}$-selective ChemFETs based on a novel ionophore: bis(phenylbenzo)-13-azocrown-5", Sensors and Actuators B, 58 (1999) 384-388

[8] J.A.J. Brunink, J.R. Haak, J.G. Bomer and D. Reinhoudt: "Chemically modified field effect transistors; a sodium ion selective sensor based on calix[4]arene receptor molecules", Analytica Chimica Acta, 254 (1991) 75-80

[9] J. Muñoz, C. Jimenez, A. Bratov, J. Bartroli, S. Alegret and C. Dominguez: "Photosensitive polyurethanes applied to the development of ChemFET and EnFET devices for biomedical sensing”, Biosensors and Bioelectronics, 12 (1997) 577-585 
[10] A. Ipatov, N. Abramova, A. Bratov and C. Dominguez: "Integrated multisensor chip with sequential injection technique as a base for "electronic tongue" devices", Sensors and Actuators $B, 131(2008) 48-52$

[11] N. Abramova and A. Bratov: "Photocurable polymers for ion selective field effect transistors. 20 Years of Applications", Sensors, 9 (2009) 7097-7110

[12] W. Sant, P. Temple-Boyer, E. Chanié, J. Launay and A. Martinez: "On-line monitoring of urea using enzymatic field effect transistors", Sensors and Actuators B, B160 (2011) 59-64

[13] Y. Tsujimura, M. Yokoyama and K. Kimura: "Comparison between silicone-rubber membranes and plasticized poly(vinyl chloride) membranes containing calix[4]arene ionophores for sodium ion-sensitive field-effect transistors in applicability to sodium assay in human body fluids", Sensors and Actuators B, 22 (1994) 195-199

[14] H.J. Lee, H.J. Oh, G. Cui, G.S. Cha and H. Nam: “All solid state sodium selective electrodes based on room temperature vulcanizing type silicone rubber matrix", Analytical Sciences, 13 (1997) 289-294

[15] I. Humenuyk, B. Torbiéro, S. Assié Souleille, R. Colin, X. Dollat, B. Franc, A. Martinez and P. Temple-Boyer: "Development of pNH4-ISFET microsensors for water analysis", Microelectronics Journal, 37 (2006), 475-479

[16] J.A.J. Brunink: "The design of durable $\mathrm{Na}^{+}$selective ChemFETs based on polysiloxane membranes", Journal of Electroanalytical Chemistry, 378 (1994) 185-200

[17] K. Kimura: "Silicone-rubber membrane sodium-ion sensors based on calix[4]arene neutral carriers", Pure and Applied Chemistry, 67 (1995) 1085-1089

[18] D.N. Reinhoudt: "Durable chemical sensors based on field effect transistors", Sensors and Actuators B, 24-25 (1995) 197-200

[19] S.J. Harris: "Chemically modified field effect transistors; a sodium ion selective sensor based on calix[4]arene receptor molecules", Analytica Chimica Acta, 254 (1991) 75-80 
[20] C. Dumschat, S. Alazard, S. Adam, M. Knoll, K. Camman: "Filled fluorosiloxane as matrix for ion-selective membranes", Analyst, 121 (1996) 527-529

[21] G. Hogg, O. Lutze and K. Camman: "Novel membrane material for ion-selective field effect transistors with extended lifetime and improved selectivity", Analytica Chimica Acta, 335 (1996) 103-109

[22] P. Temple-Boyer, J. Launay I. Humenyuk, T. Do Conto, A. Martinez, C. Bériet and A. Grisel: "Study of front-side connected chemical field effect transistors for water analysis", Microelectronics Reliability, 44 (2004) 443-447

[23] http://www.silicones-science.com/chemistry/

[24] Y. Umezawa, K. Umezawa, H. Sato: "Selectivity coefficients for ion-selective electrodes: recommended methods for reporting KABpot values", Pure and Applied Chemistry, 67 (1995) 507-518

[25] M.W. Shinwari: "Microfabricated reference electrodes and their biosensing applications", Sensors, 10 (2010) 1679-1715

[26] L. Tymecki: "Screen-printed reference electrodes for potentiometric measurements", Analytica Chimica Acta, 526 (2004) 3-11

[27] M.W. Shinwari, D. Zhitomirsky, I.A. Deen, P.R. Selvaganapathy, M.J. Deen and D. Landheer: "Microfabricated reference electrodes and their biosensing applications", Sensors, 10 (2010) 1679-1715

[28] I.J. Yoon, D.K. Lee, H. Nam, G.S. Cha, T.D. Strong and R.B. Brown: "Ion sensors using onecomponent room temperature vulcanized silicone rubber matrices", Journal of Electroanalytical Chemistry, 464 (1999) 135-142

\section{Biographies}

Arnaud Cazalé was born on November 19, 1985. He received his Master's Degree in electronics embedded micro-systems from the University Paul Sabatier de Toulouse (France) in 2009. He 
joined HEMODIA company (France) in the same time and started his $\mathrm{PhD}$ in collaboration with the Laboratoire d'Architecture et d'Analyse des Systèmes of the French Centre National de la Recherche Scientifique (LAAS-CNRS) to develop sodium sensitive ChemFET microsensors for medical applications.

William Sant was born on May 18, 1969. He received his Master's Degree in electronics in 1996 and his Diplome d'Etudes Approfondies in Microelectronics from the Université Paul Sabatier de Toulouse (France) in 1999. He joined the Laboratoire d'Architecture et d'Analyse des Systèmes of the French Centre National de la Recherche Scientifique (LAAS-CNRS) in 2000 and received the $\mathrm{PhD}$ degree from the Université Paul Sabatier de Toulouse (France) in 2004. Since then, he has joined the HEMODIA company (France) as an R\&D engineer and has been working on the development of ChemFET microsensors for medical applications.

Jérôme Launay was born the $11^{\text {th }}$ of March 1975. He received the degree in electronic engineering from the Institut National des Sciences Appliquées de Toulouse" (France) in 1998. He joined the Laboratoire d'Architecture et d'Analyse des Systèmes from the French "Centre National de la Recherche Scientifique" (LAAS-CNRS) in 1998 and received the PhD degree from the Institut National des Sciences Appliquées de Toulouse (France) in 2001. In 2002, he became lecturer at the Université Paul Sabatier de Toulouse (France). His research activities include the development of chemical microsensors for the detection in liquid phase.

Frédéric Ginot was born on September 1962. He received his Engineer Master's Degree from the Ecole Polytechnique (Paris - France) in 1985 and a $\mathrm{PhD}$ in molecular biology from Paris University VII in 1989. After various jobs in R\&D, at the interface between engineering and biosciences, he joined HEMODIA/CAPTOMED company as vice-president for Research \& Development in 2010 . 
Pierre Temple-Boyer was born on October 25, 1966. He received his Engineer Master's Degree in electronic engineering from the Ecole Supérieure d'Electricité (Paris - France) in 1990 and his Master's Degree in microelectronics from the Université Paul Sabatier de Toulouse (France) in 1992. He joined the Laboratoire d'Architecture et d'Analyse des Systèmes of the French Centre National de la Recherche Scientifique (LAAS-CNRS) in 1992 and received the $\mathrm{PhD}$ degree from the Institut National des Sciences Appliquées de Toulouse (France) in 1995. Since then, as a senior researcher, he has been working on the development of micro- and nanotechnologies. 


\section{Tables and figures caption}

Table 1: FPSX patterns typical dimensions according to ejection time (ejection pressure $\Delta \mathrm{P}: 48.3 \mathrm{~Pa}$ )

Table 2: Comparison of published pNa-ISFET performances

Figure 1: schematic cross-section of the ChemFET device and mass fabrication of ChemFET chips (size: $2.1 \times 1.6 \mathrm{~mm}^{2}$ ) in silicon foundry

Figure 2: fluoropolysiloxane reticulation due to atmospheric moisture

Figure 3: fabrication of the $\mathrm{pNa}-\mathrm{ISFET} / \mathrm{pH}-\mathrm{ChemFET}$ detection module with an integrated $\mathrm{Ag} / \mathrm{AgCl}$ gate reference electrode

Figure 4: geometrical properties of spherical segments

Figure 5: profilometric characterization of FPSX-based droplets (ejection pressure $\Delta \mathrm{P}: 34.5 \mathrm{~Pa}$, ejection time $\mathrm{t}: 1 \mathrm{~ms}$ )

Figure 6: $\mathrm{pCl}$ analytical response of the integrated $\mathrm{Ag} / \mathrm{AgCl}$ reference electrode

Figure 7: calibration curves of the of the integrated $\mathrm{Ag} / \mathrm{AgCl}$ reference electrode 
Figure 8: Nernst potential temporal variations (in a $0.1 \mathrm{M} \mathrm{NaCl}$ solution) for the integrated $\mathrm{Ag} / \mathrm{AgCl}$ reference electrode

Figure 9: $\mathrm{pH}$ responses of the $\mathrm{pNa}-\mathrm{ISFET} / \mathrm{pH}-\mathrm{ChemFET}$ module

Figure 10: analytical response of the sodium ion $\mathrm{Na}^{+}$concentration $\underline{\text { using an } \mathrm{Ag} / \mathrm{AgCl} \text { glass double junction reference electrode }}$

Figure 11: calibration curves of the pNa-ISFET $\underline{\text { using an } \mathrm{Ag} / \mathrm{AgCl} \text { glass double junction reference electrode }}$

Figure 12: analytical response and calibration curve (insert) of the pNa-ISFET using the integrated " $\mathrm{Ag} / \mathrm{AgCl}$ ink" reference electrode

Figure 13: analysis of real sweat samples using the $\mathrm{pNa}$-ISFET microsensor 


\begin{tabular}{|c|c|c|c|c|c|c|c|c|c|c|}
\hline ejection time $(\mathrm{ms})$ & 1 & 2 & 3 & 4 & 5 & 6 & 7 & 8 & 9 & 10 \\
\hline upper radius a $(\mu \mathrm{m})$ & 220 & 270 & 280 & 325 & 360 & 375 & 400 & 405 & 435 & 475 \\
\hline lower radius b $(\mu \mathrm{m})$ & 575 & 665 & 730 & 775 & 840 & 900 & 965 & 1005 & 1055 & 1075 \\
\hline height $\mathrm{h}(\mu \mathrm{m})$ & 7.5 & 9.9 & 11.2 & 11.6 & 12.8 & 14 & 15.1 & 15.6 & 16.7 & 17.2 \\
\hline
\end{tabular}

Table 1: FPSX patterns typical dimensions according to ejection time (ejection pressure $\Delta \mathrm{P}: 48.3 \mathrm{~Pa}$ ) 


\begin{tabular}{|c|c|c|c|c|c|c|c|c|}
\hline $\begin{array}{l}\text { ion-sensitive } \\
\text { membrane }\end{array}$ & $\begin{array}{c}\text { PVC } \\
{[5]}\end{array}$ & $\begin{array}{c}\text { PVC } \\
{[6]}\end{array}$ & $\begin{array}{c}\text { PVC } \\
{[7]}\end{array}$ & $\begin{array}{c}\text { PVC } \\
{[8]}\end{array}$ & $\begin{array}{l}\mathrm{PU} \\
{[10]}\end{array}$ & $\begin{array}{l}\text { PSX } \\
{[16]}\end{array}$ & $\begin{array}{r}\text { FPSX } \\
{[21]}\end{array}$ & $\begin{array}{c}\text { FPSX } \\
\text { (this work) }\end{array}$ \\
\hline $\begin{array}{l}\text { sensitivity } \\
(\mathrm{mV} / \mathrm{pNa})\end{array}$ & $56-59$ & 50 & $47-52$ & 57 & $54-56$ & $53-57$ & 56 & $56-58$ \\
\hline $\begin{array}{l}\text { detection } \\
\text { limit }(\mathrm{M})\end{array}$ & $3 \times 10^{-4}$ & $\sim 10^{-5}$ & $\sim 10^{-4}$ & $\sim 10^{-4}$ & $\sim 10^{-4}$ & $\sim 10^{-4}$ & - & $\sim 10^{-4}$ \\
\hline $\begin{array}{c}\text { selectivity } \\
\left(\log \mathrm{K}_{\mathrm{Na}+/ \mathrm{K}^{+}}\right)\end{array}$ & -1.3 & -1.8 & -1.7 & -1.5 & - & -2.6 & -2.3 & -3 \\
\hline $\begin{array}{l}\text { response } \\
\text { time (s) }\end{array}$ & - & 60 & 2 & - & - & $50-60$ & - & 50 \\
\hline $\begin{array}{c}\text { temporal } \\
\text { drift }(\mathrm{mV} / \mathrm{h})\end{array}$ & - & - & - & - & 0.1 & - & - & 0.3 \\
\hline
\end{tabular}

Table 2: Comparison of published $\mathrm{pNa}$-ISFET performances 

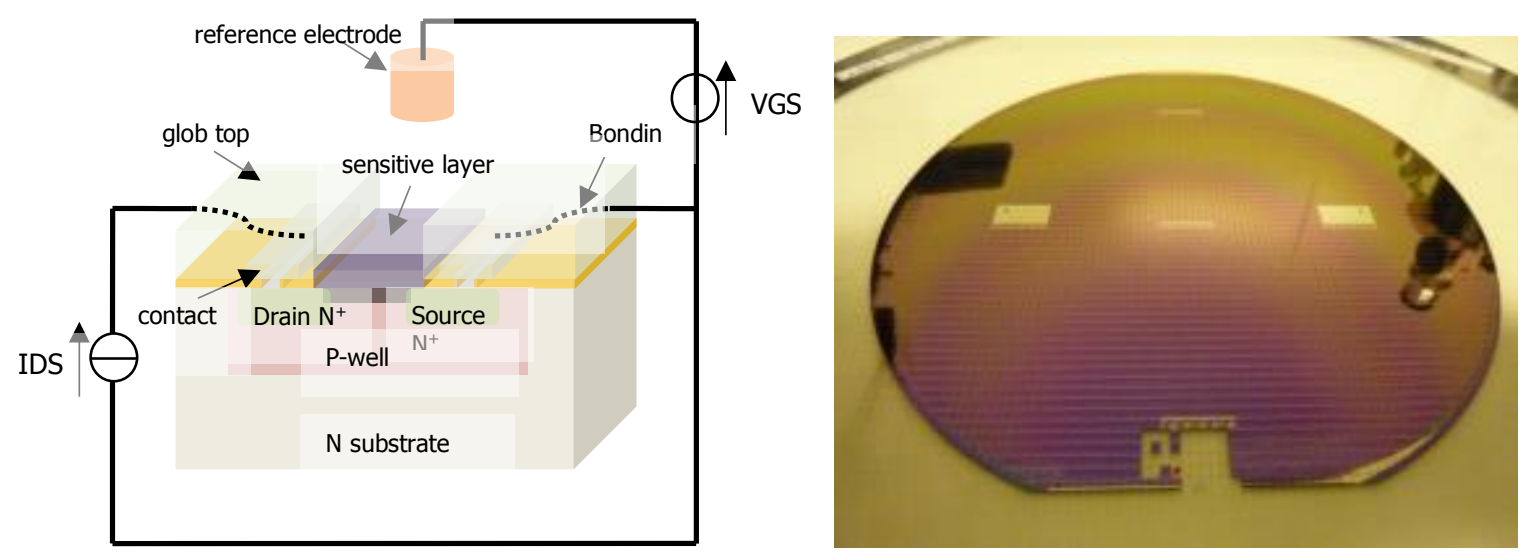

Figure 1: schematic cross-section of the ChemFET device and mass fabrication of ChemFET chips (size: $2.1 \times 1.6 \mathrm{~mm}^{2}$ ) in silicon foundry 


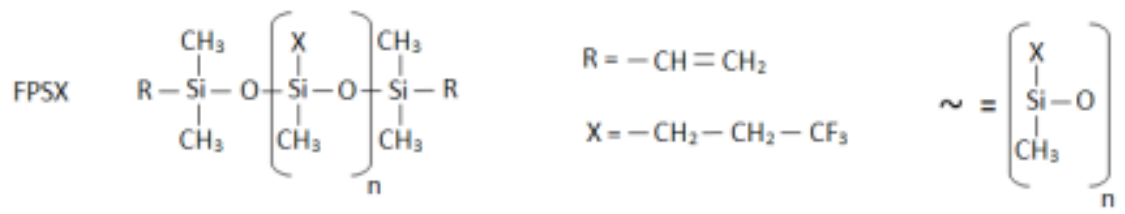

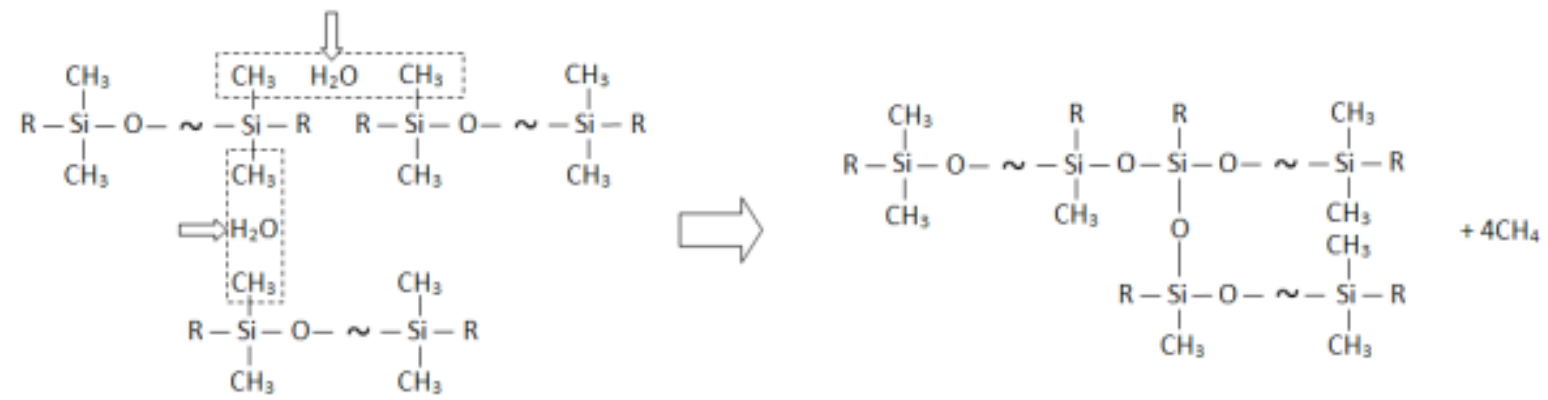

Figure 2: fluoropolysiloxane reticulation due to atmospheric moisture 


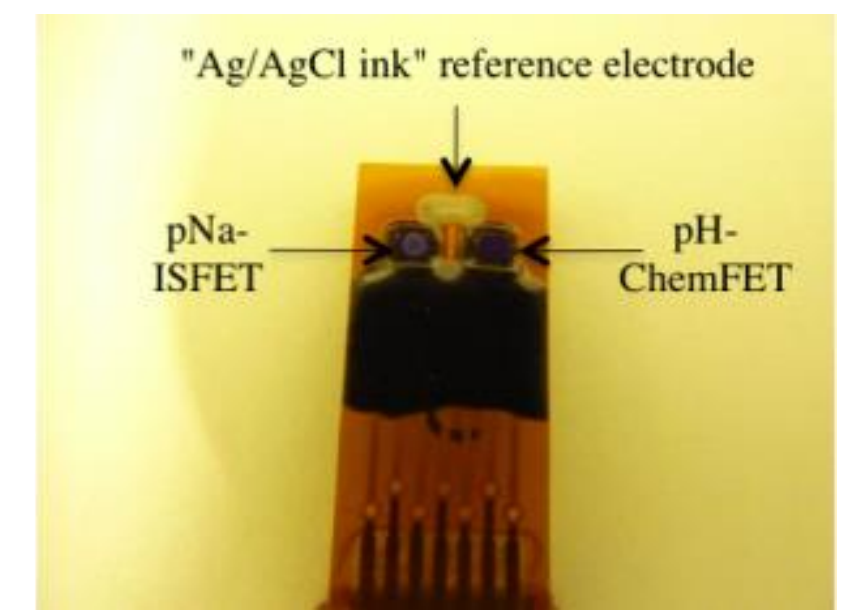

Figure 3: fabrication of the $\mathrm{pNa}-\mathrm{ISFET} / \mathrm{pH}-\mathrm{ChemFET}$ detection module with an integrated $\mathrm{Ag} / \mathrm{AgCl}$ gate reference electrode 


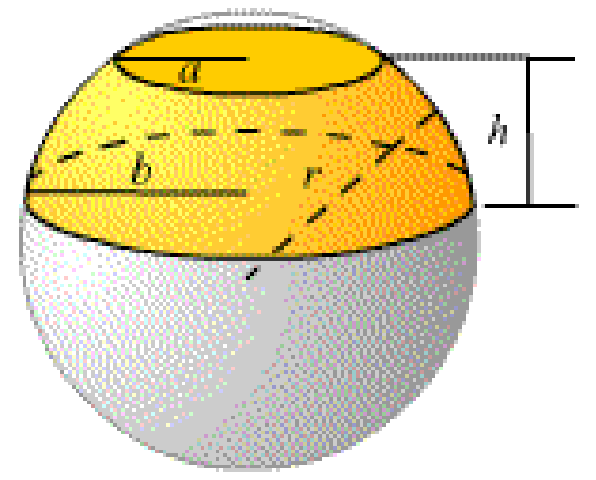

Figure 4: geometrical properties of spherical segments 


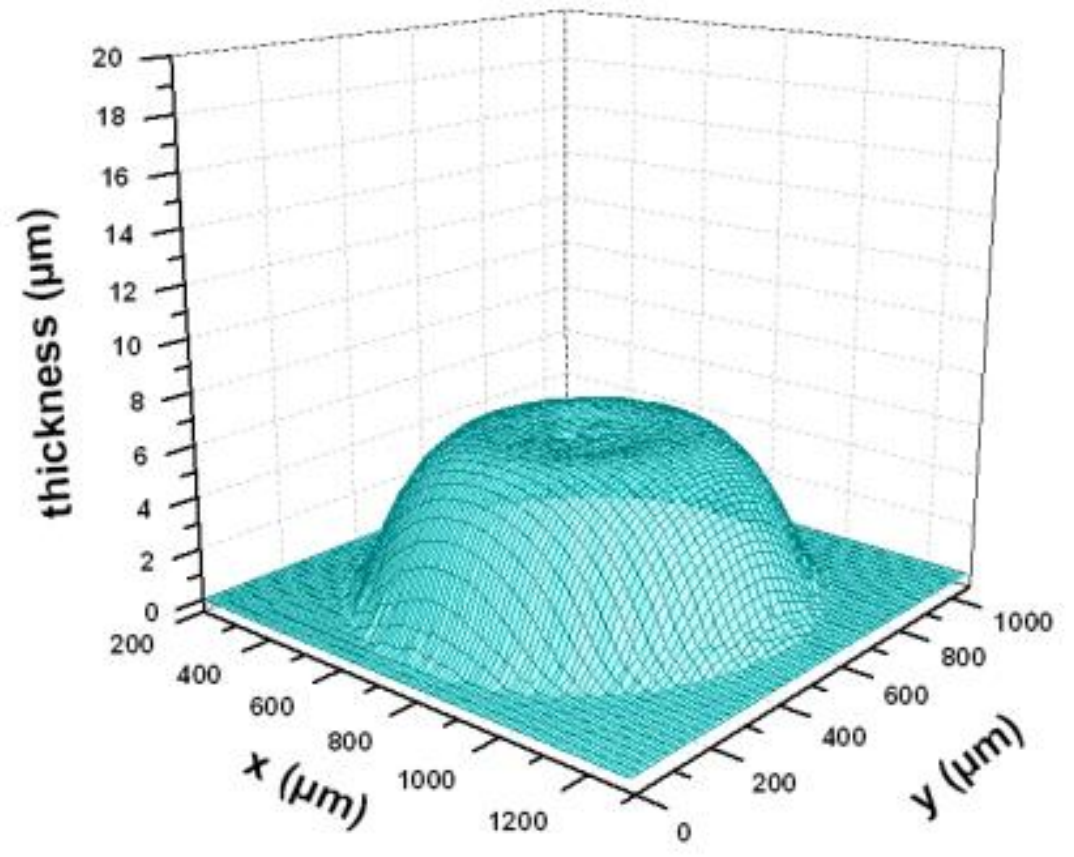

Figure 5: profilometric characterization of FPSX-based droplets (ejection pressure $\Delta \mathrm{P}: 34.5 \mathrm{~Pa}$, ejection time $\mathrm{t}: 1 \mathrm{~ms}$ ) 


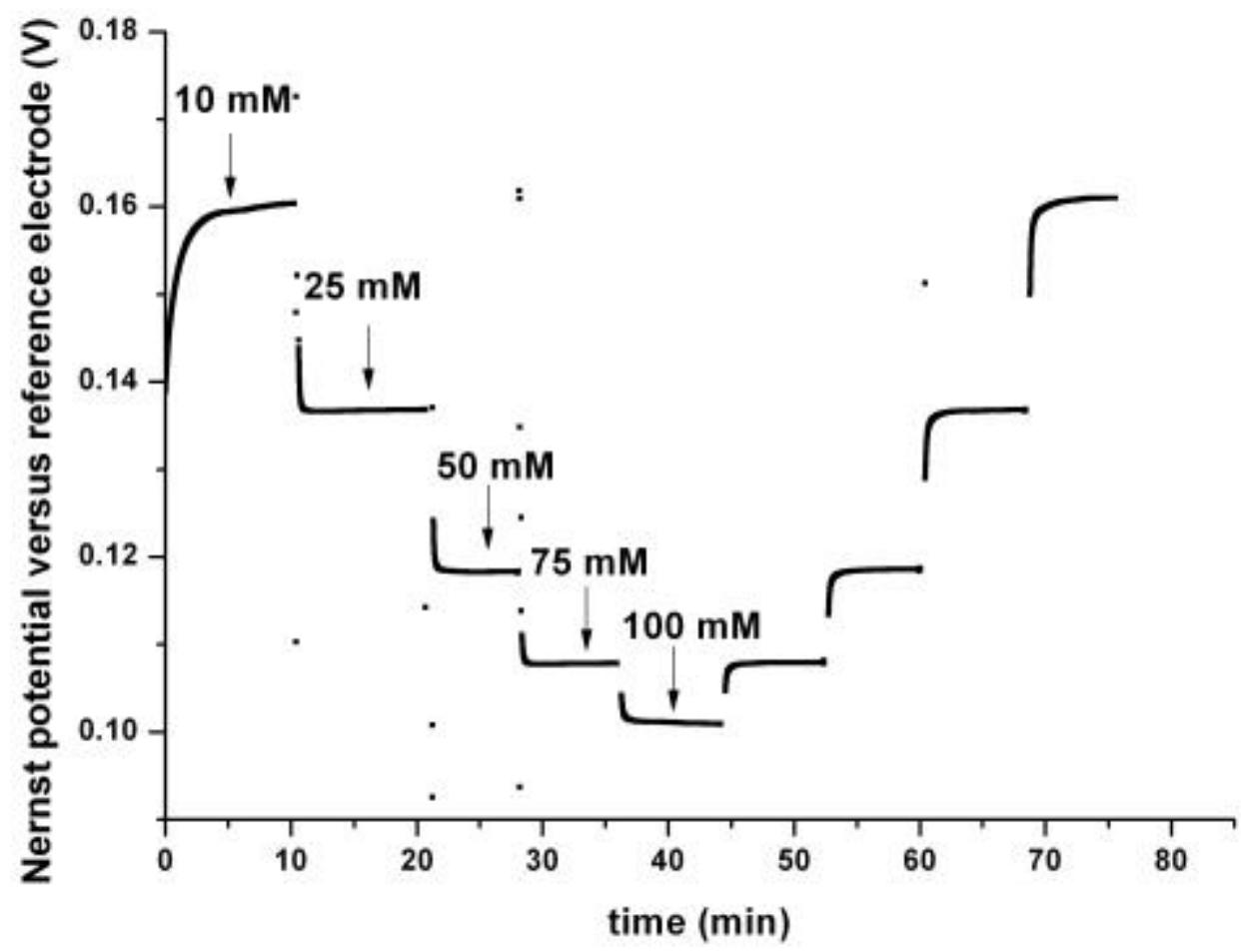

Figure 6: $\mathrm{pCl}$ analytical response of the integrated $\mathrm{Ag} / \mathrm{AgCl}$ reference electrode 


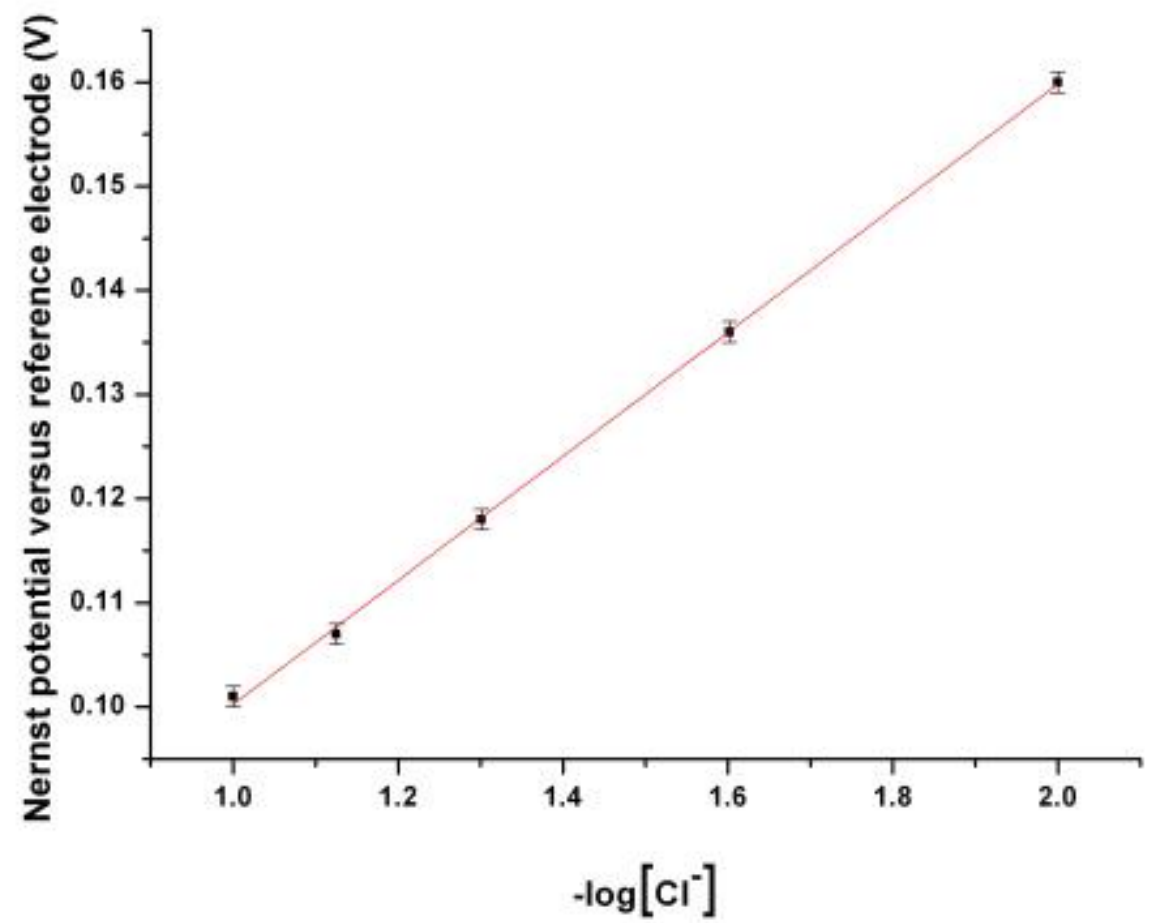

Figure 7: $\mathrm{pCl}$ analytical response of the integrated $\mathrm{Ag} / \mathrm{AgCl}$ reference electrode 


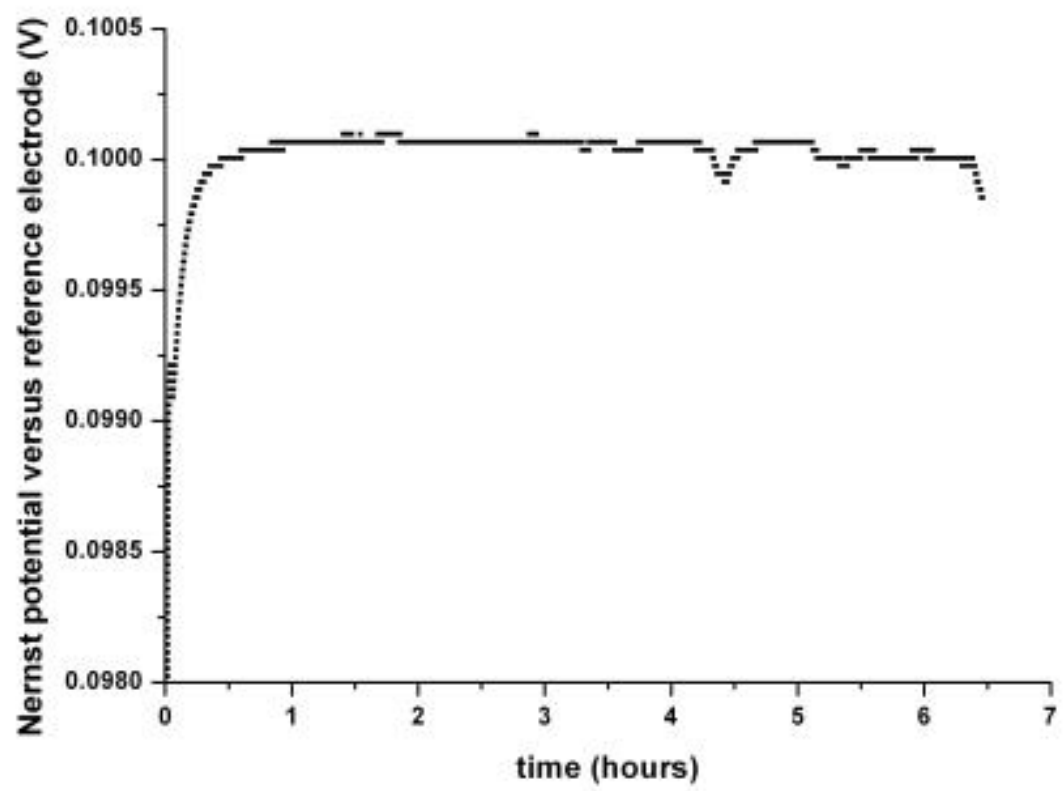

Figure 8: Nernst potential temporal variations (in a $0.1 \mathrm{M} \mathrm{NaCl}$ solution) for the integrated $\mathrm{Ag} / \mathrm{AgCl}$ reference electrode 


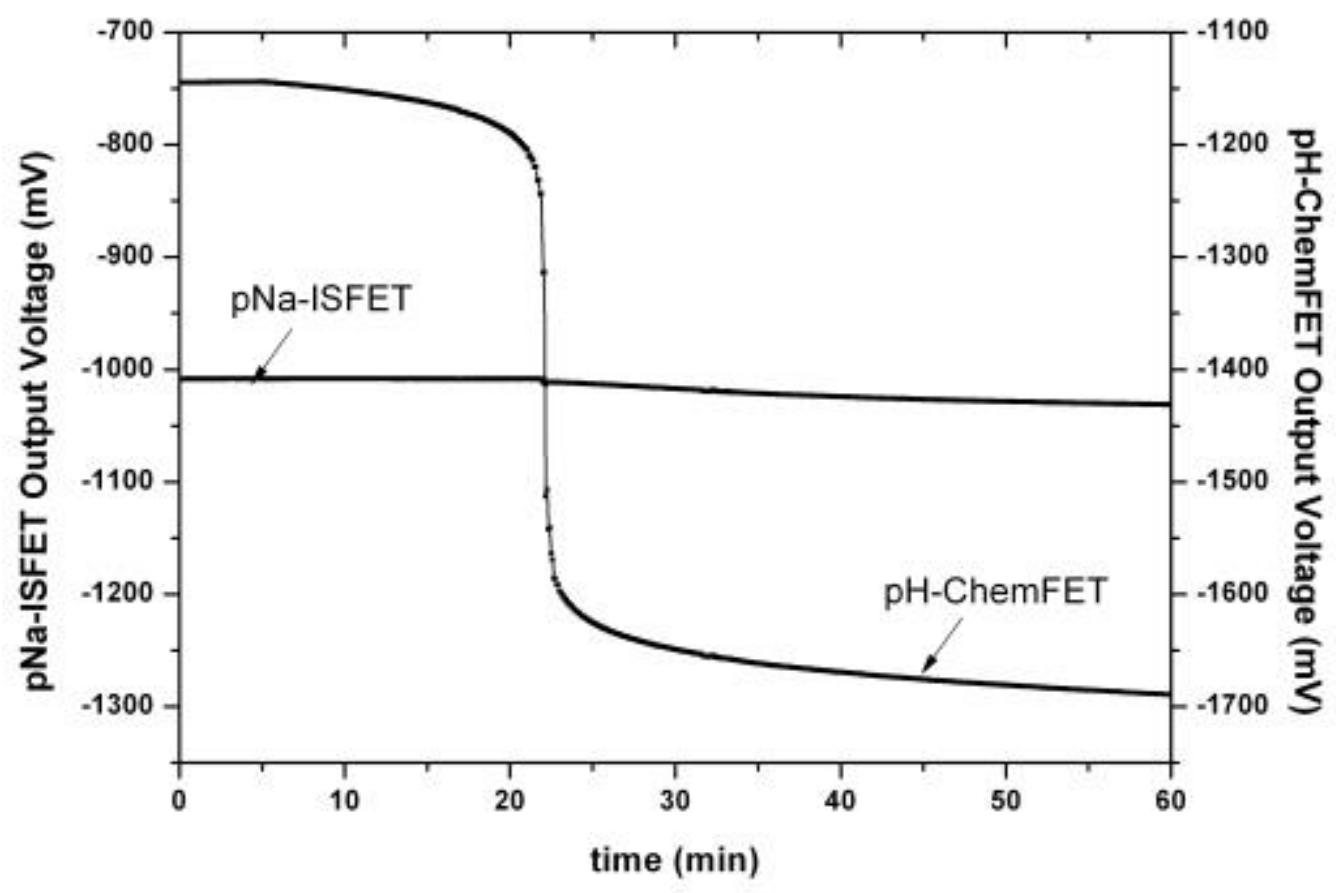

Figure 9: $\mathrm{pH}$ responses of the $\mathrm{pNa}-\mathrm{ISFET} / \mathrm{pH}-\mathrm{ChemFET}$ module 


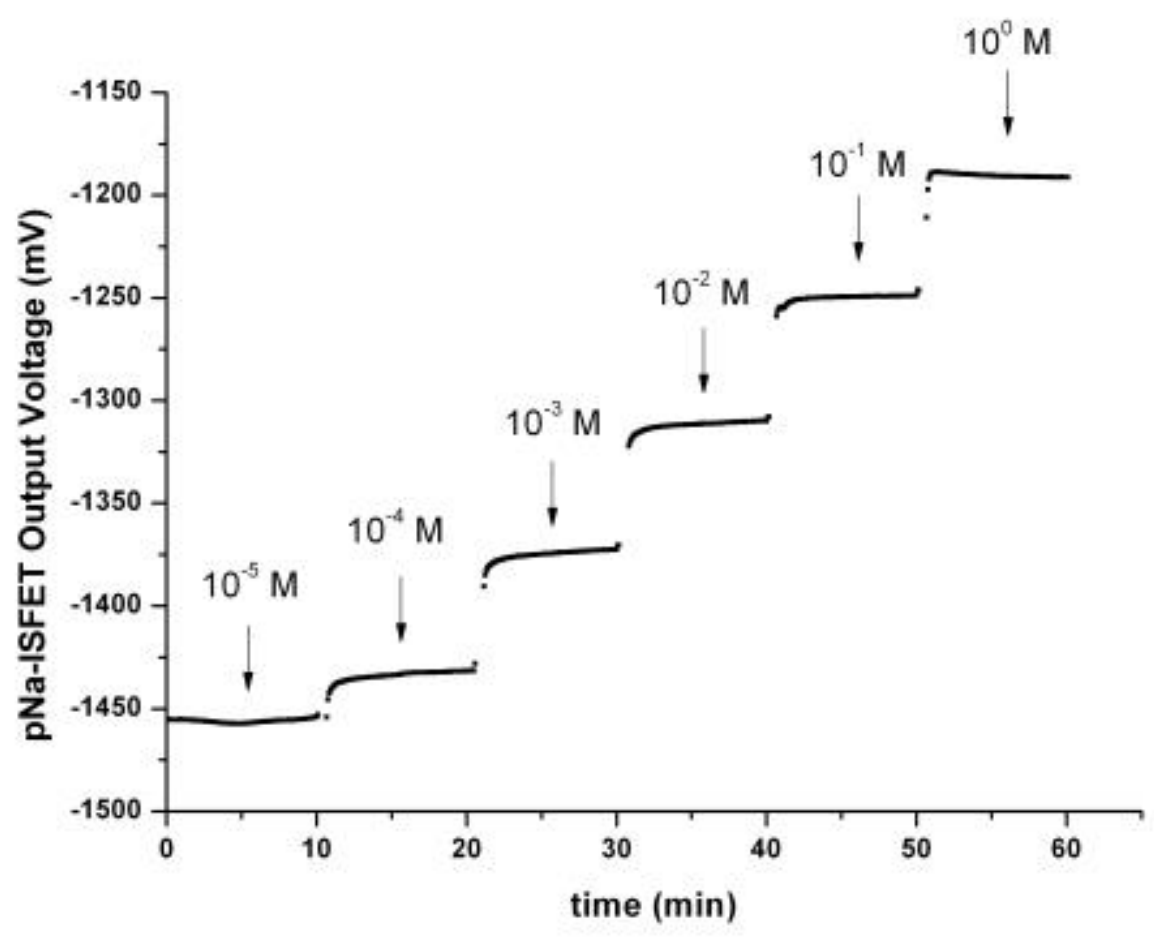

Figure 10: analytical response of the sodium ion $\mathrm{Na}^{+}$concentration $\underline{\text { using an } \mathrm{Ag} / \mathrm{AgCl} \text { glass double junction reference electrode }}$ 


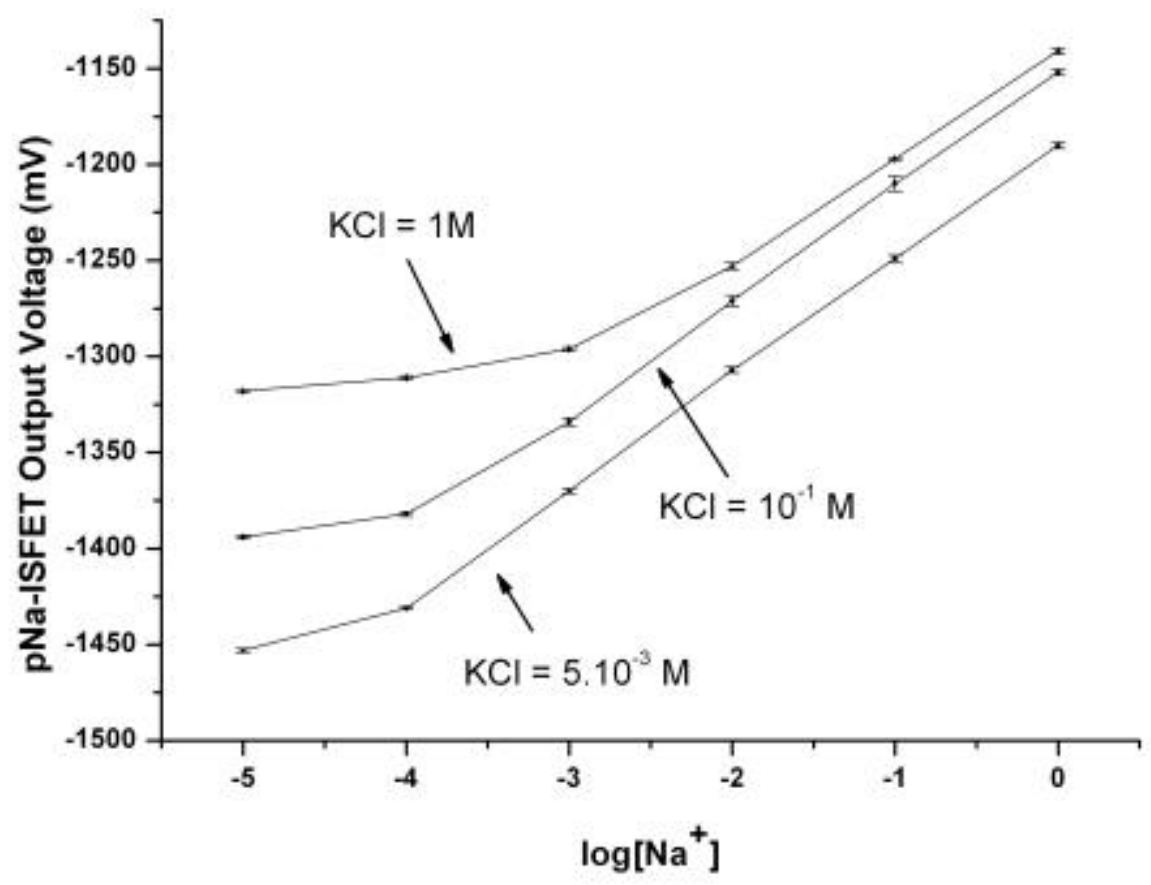

Figure 11: calibration curves of the pNa-ISFET $\underline{\text { using an } \mathrm{Ag} / \mathrm{AgCl} \text { glass double junction reference electrode }}$ 


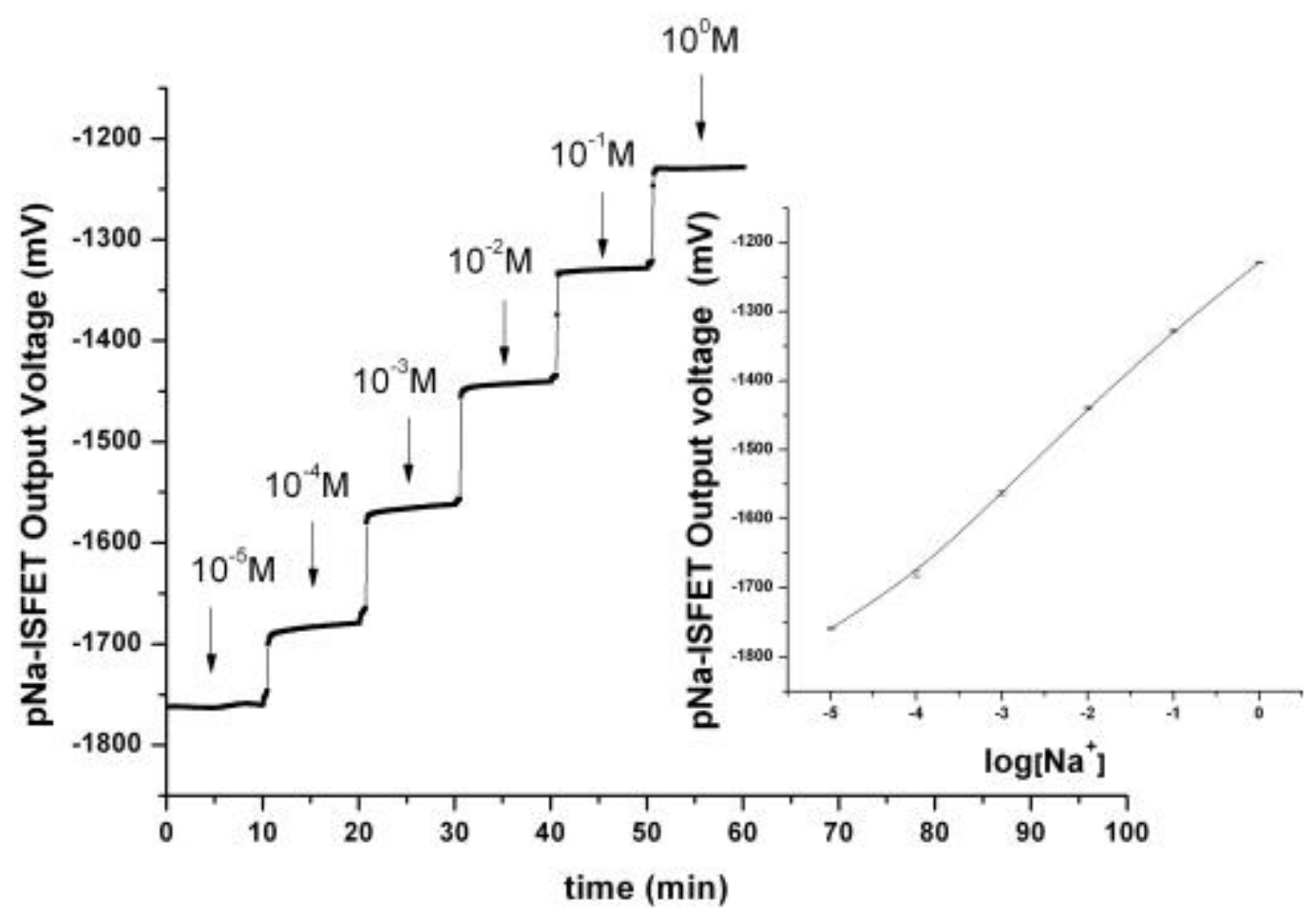

Figure 12: analytical response and calibration curve (insert) of the $\mathrm{pNa}$-ISFET using the integrated " $\mathrm{Ag} / \mathrm{AgCl}$ ink" reference electrode 


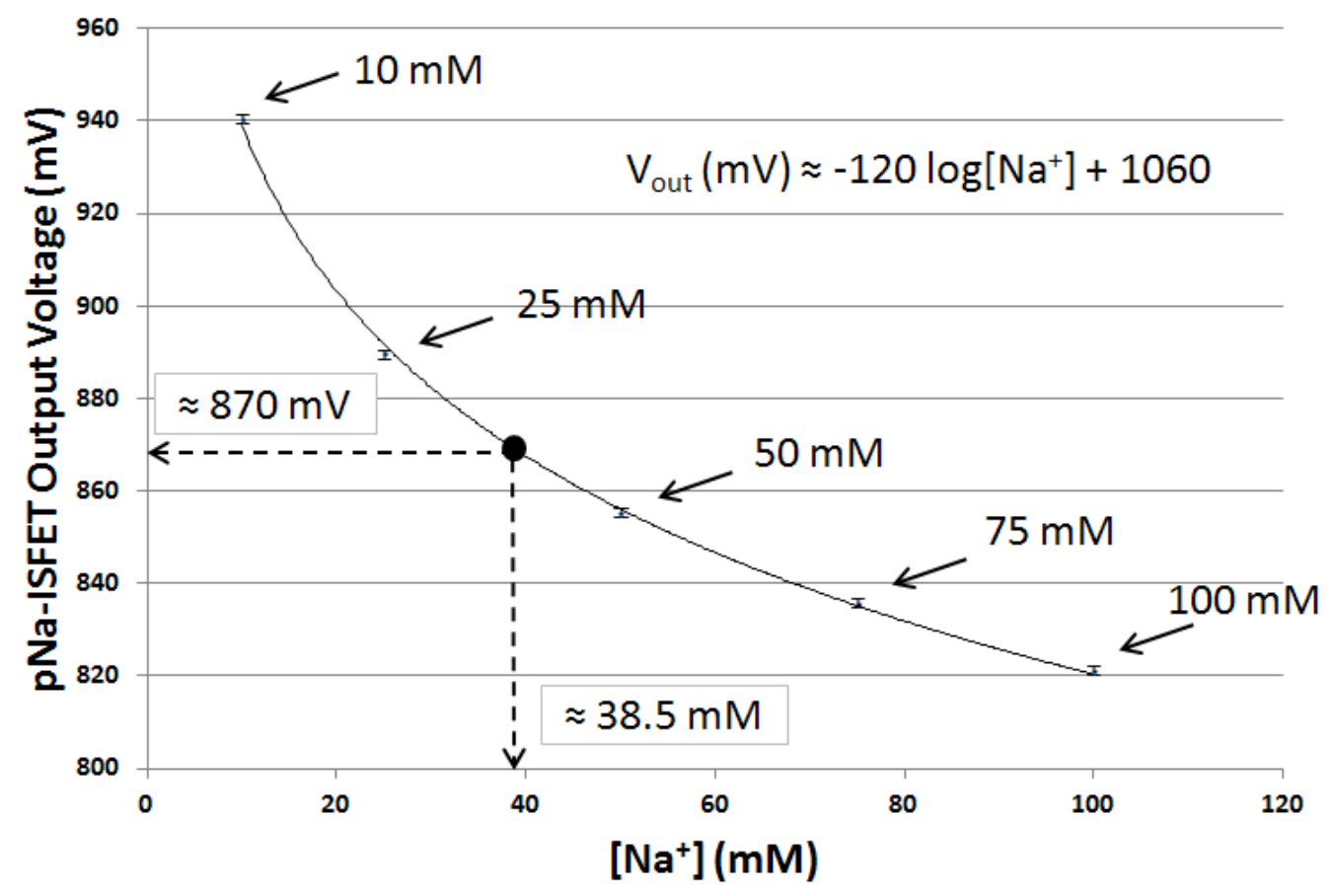

Figure 13: analysis of real sweat samples using the pNa-ISFET microsensor 